\title{
PELATIHAN MAHIR MENGETIK TULISAN ARAB BAGI MAHASISWA BARU PRODI PENDIDIKAN BAHASA ARAB
}

\author{
Yayah Robiatul Adawiyah ${ }^{1}$, Khoirun Nisa, ${ }^{,}$, Rika Agustin ${ }^{3,}$ Sri Wahyuni ${ }^{4}$, \\ Hajar Rosdiana ${ }^{5}$, Nurul Latifah ${ }^{6}$ \\ ${ }_{1,2,3,4,5,6)}$ Program Studi Pendidikan Bahasa Arab, Fakultas Agama Islam, Universitas Nurul Jadid \\ e-mail:ya2hsoebandi@gmail.com
}

\begin{abstract}
Abstrak
Pelatihan adalah suatu proses pendidikan jangka pendek dengan menggunakan prosedur-prosedur yang sistimatis dan terorganisir, sehingga karyawan belajar mengenai pengetahuan teknik dan keahlian untuk tujuan tertentu. Mengetik bahasa arab merupakan suatu kegiatan yang sangat penting terutama bagi mahasiswa jurusan pendidikan bahasa arab maupun sastra arab, Mengetik tulisan Arab merupakan salah satu bentuk keterampilan yang diharapkan dari pembelajaran bahasa Arab. Bahasa Arab sebagai bahasa asing, maka tidak mustahil bagi seseorang akan menemui kesulitan dalam mempelajarinya dan kesalahan dalam menulisnya. Universitas Nurul Jadid memiliki mahasiswa jurusan Pendidikan Bahasa Arab yang sudah sangat banyak akan tetapi mereka masih lemah bahkan tidak bisa mengetik Arab dengan lancar dan benar. Dalam memperoleh mahasiswa yang terampil dan mahir dalam mengetik huruf-huruf Arab baik melalui laptop ataupun komputer maka selaku dosen pendidikan bahasa arab harus mengadakan pelaksanaan pelatihan dengan tujuan membantu mahasiswa agar lebih mahir dalam mengetik tulisan arab pada laptop/komputer. Adapun metode yang kami gunakan dengan melalui 2 tahapan: pertama; persiapan dan kedua; pelaksanaan pelatihan. Setelah melakukan pelatihan terhadap mahasiswa baru prodi PBA Universitas Nurul Jadid maka, hasil pengabdian yang dilakukan selama 2 hari dilihat dari hasil evaluasi menunjukkan adanya perkembangan yang sangat pesat dari sebelumnya, dari sini pengabdian kepada masyarakat ini dinyatakan berhasil dan sukses.
\end{abstract}

Kata kunci: Pelatihan, Mahir, Mengetik Tulisan Arab.

\begin{abstract}
Training is a short-term educational process using systematic and organized procedures, so that employees learn technical knowledge and skills for specific purposes. Typing Arabic is a very important activity, especially for students majoring in Arabic education and Arabic literature. Typing Arabic script is one of the skills expected from learning Arabic. Arabic as a foreign language, it is not impossible for someone to find difficulties in learning it and mistakes in writing it. Nurul Jadid University has a large number of students majoring in Arabic Language Education but they are still weak and cannot even type Arabic fluently and correctly. In obtaining students who are skilled and proficient in typing Arabic letters either through a laptop or computer, as an Arabic language education lecturer, they must conduct training with the aim of helping students to become more proficient in typing Arabic script on a laptop / computer. The method we use goes through 2 stages: first; preparation and second; implementation of training. After conducting training for new students of the Nurul Jadid University PBA study program, the result of the service that was carried out for two days, seen from the result of the evaluation show that there is a very rapid development than before, from here this community service is declared successful.
\end{abstract}

Keywords: Training, Proficient, Typing Arabic script.

\section{PENDAHULUAN}

Bahasa Arab sangatlah berperan penting untuk menumbuhkan kultur keislaman yang ada di pesantren, bahasa pada dasarnya adalah suatu system simbol vocal atau visual yang bersifat arbitrer yang digunakan oleh suatu masyarakat sebagai sarana untuk melakukan urusan sehari-hari mereka (Nor Fitriani, 2015). Pembelajaran bahasa Arab merupakan mata pelajaran yang diarahkan untuk mendorong, membimbing, mengembangkan, dan membina kemampuan serta membutuhkan sikap positif terhadap bahasa Arab baik reseptif maupun produktif (Rizqi, 2013). Kemampuan reseptif yaitu kemampuan menggunakan bahasa sebagai alat komunikasi baik secara lisan maupun tulisan. 
Secara umum di Pondok Pesantren Nurul Jadid Paiton Probolinggo khususnya para pelajar prodi pendidikan bahasa Arab Universitas Nurul Jadid yang berasal dari berbagai daerah yang sedang menekuni bidang bahasa arab atau mendalami bahasa arab masih banyak mengalami kesulitan dalam mengetik bahasa Arab menggunakan laptop/komputer sehingga sering kali mereka menggunakan huruf tempelan Arab pada keyboard. Ini kerap kali terjadi terutama bagi mahasiswa yang duduk di semester awal ( Mahasiswa baru) tulisan yang mereka tulis dengan menggunakan tempelan keyboard biasanya diketik satu persatu sehingga memerlukan waktu yang cukup banyak, tidak hanya itu mereka juga masih kesulitan dalam mengharkati tulisan mereka. Upaya-upaya sudah dilakukan agar mereka para pelajar bahasa arab khususnya prodi pendidikan bahasa arab semester awal membiasakan diri agar bisa mengetik dengan baik dan lancar namun dari usaha tersebut hanya mengubah sebagian saja.

Dari permasalahan-permasalahan tersebut maka sudah sepatutnya menjadi perhatian kita bersama kalau bukan kita siapa lagi yang peduli terhadap generasi-generasi bahasa Arab selanjutnya karena Maharah Al-kitabah merupakan salah satu bentuk keterampilan yang diharapkan untuk dikuasai peserta didik maupun mahasiswa dari pembelajaran bahasa Arab dan di dukung dengan kecanggihan teknologi sekarang yang mengharuskan kita terampil dalam mengetik mengggunakan laptop atau komputer untuk mencurahkan semua ide-ide pikiran dan menghidupkan dunia literasi. Oleh karena itu dalam pengabdian ini yang menjadi subjek dampingan adalah para Mahasiswa prodi pendidikan bahasa arab semester 2 (mahasiswa baru). berdasarkan perundingan dengan pengurus maka persoalan prioritas yang akan ditangani dalam pengabdian ini adalah: pertama; peserta didik masih belum antusias dalam kegiatan kebahasaan sehingga perlu motivasi lanjutan bagi mereka, kedua; sebagian besar anak didik masih belum bisa mengetik bahasa arab dengan baik dan benar., ketiga; sebagian kecil sudah bisa mengetik bahasa arab sesuai tanpa tempelan huruf namun masih perlu pembiasaan. Maka berangkat dari alasan ini kami selaku Dosen dan Mahasiswa pendidikan bahasa Arab melakukan pengabdian kepada masyarakat dengan tema Pelatihan Mahir Mengetik Tulisan Arab bagi Mahasiswa Baru Prodi Pendidikan Bahasa Arab.

\section{METODE}

Pelatihan Mahir mengetik tulisan Arab dalam bentuk pendampingan dalam pembelajaran, yang mana semua pihak dilibatkan secara aktif. Dalam menganalisis tahapan-tahapan kegiatan yang sedang berlangsung untuk melakukan perubahan-perubahan lebih baik lagi. Adapun langkahlangkah yang sesuai dengan metode ABCD yaitu pada siklus 5-D: Define, Discovery, Dream, Design, dan destiny (SK. Dirjen Pendidikan Islam, 2020: 33-34). dilaksanakan sebagai berikut:

1. Define (Penentuan): pelatihan atau pelaku pemberdayaan menentukan "pilihan topik" dalam melakukan pendampingan di masyarakat. Topik yang ditentukan di jurusan pendidikan bahasa Arab dengan mengadakan pelatihan mahir mengetik tulisan arab pada laptop/komputer.

Para Fasilitator menyiapkan segala sesuatu untuk kegiatan. Selain itu Fasilitator juga akan berkoordinasi kepada seluruh kosma (ketua kelas) semester 2 serta pengurus wilayah, dalam rangka persiapan untuk pelaksanaan kegiatan baik jadwal maupun persiapan alat dan bahan dalam kegiatan.

3. Discovery (Penemuan Mendalam): adalah pendampingan atau para fasilitator melakukan proses pencarian yang mendalam, seperti mencari dan mengidentifikasi kemampuan yang dimiliki para peserta latihan, masalah yang dihadapi dan lain sebagainya. Untuk melaksanakan dan mengoptimalkan proses Discovery yaitu melakukan silaturrahmi ke lembaga komunitas latihan tersebut. Dalam pertemuan inilah fasilitator mengerti dan memahami batas kemampuan peserta didik dalam mengetik lafadz arab, targetnya adalah memberi pemahaman kepada peserta didik agar mahir dalam mengetik lafadz arab Setelah dirasa paham dan mampu, secara individual mereka diminta untuk mengetik di laptop masing-masing sebanyak tiga baris. Para Fasilitator akan mengecek perkembangan mengetik para peserta didik. Pada tahap ini dilakukan penilaian kemampuan mengetik peserta didik dengan lembar penilaian guna menilai keberhasilan program dan Evaluasi kedepan.

4. Dream (Impian): dream merupakan mimpi atau keinginan atau bisa tujuan yang diharapkan komunitas latihan dalam mengembangkan aset komunitas tersebut. Setelah 
menemukan aset tersebut selanjutnya adalah merumuskan keinginan atau tujuan untuk mengembangkan aset tersebut.

5. Design (perancangan): pada tahap ini pendamping atau pelatih dengan komunitas dampingan dan sebagainya memulai untuk merumuskan strategi, proses dan system membagi peran dan bertanggung jawab, membuat keputusan dan mengembangkan kolaborasi yang mendukung terwujudnya penyelesaian masalah.

6. Deliver atau Destiny (pelaksanaan, kontrol, dan evaluasi): didalam tahapan ini, terdapat beberapa tahapan yang dilakukan. Tahapan ini dilakukan setelah melalui proses define, discovery, dream, dan design yang sudah dilakukan di prodi Pendidikan Bahasa Arab semester 2 .

\section{HASIL DAN PEMBAHASAN \\ Dampak Perubahan}

a. Perubahan pada aspek proses Pelatihan mengetik tulisan Arab pada mahasiswa baru prodi PBAdi Universitas Nurul Jadid Paiton Probolinggo

Sesuai dengan metode ABCD yang digunakan dalam proses pelatihan ini, maka dijelaskan sebagai berikut:

Pertama, Define. Pelatih dan seluruh fasilitator menentukan " pilihan topik" dalam mengadakan pelatihan di masyarakat. Di dalam tahapan ini terdapat beberapa langkah yang dilakukan yaitu: a) menetukan topik. Topik ini ditentukan pada tanggal 10 januari 2021 oleh kelompok KKN dan DPL. Topik yang ditentukan yaitu: pelatihan mahir mengetik tulisan arab bagi mahasiswa baru (semester II) prodi Pendidikan Bahasa Arab di Universitas Nurul Jadid Paiton Probolinggo guna membantu mahasiswa agar semakin mahir dan cepat serta benar dalam mengetik Arab melalui komputer ataupun laptop; b) menentukan peserta latihan. Setelah melalui rapat dan koordinasi antara kelompok dan DPL maka peserta yang akan dikembangkan asetnya adalah mahasiswa baru atau semester II Prodi PBA; c) melakukan izin kepada lembaga pondok pesantren Nurul Jadid untuk melakukan pelatihan di Universitas Nurul Jadid Paiton Probolinggo pada tanggal 14-15 maret 2021. Surat izin melaksanakan pengabdian kepada masyarakat ini disetujui dan ditanda tangani oleh pihak LP3M UNUJA.

Kedua, Discovery. Pada tahapan ini pelatih dan fasilitator melakukan proses pencarian yang mendalam, seperti mencari dan mengidentifikasi aset yang dimiliki peserta pelatihan, masalah yang dihadapi peserta dan sebagainya. Untuk melaksanakan dan mengoptimalkan proses Discovery yaitu melakukan silaturrahmi ke lembaga komunitas latihan tersebut salah satu hasilnya adalah hasil wawancara dengan kosma pada masing-masing kelas yakni sebagai berikut: " bahwa mahasiswa/i baru prodi PBA ada sekitar $80 \%$ belum lancar bahkan belum bisa mengetik Arab menggunakan komputer maupun laptop, sebagian mereka mengetik dengan menggunakan huruf Arab tempelan pada keybord dan belum tau cara mengubah font indonesia ke arab, cara mengharkati, cara mengetik dari kanan ke kiri dan masih banyak masalah-masalah lainnya". Hasil wawancara di atas menunjukkan bahwa perlu adanya pelatihan secara mendalam mengenai mengetik bahasa Arab ini mengingat menulis (maharah al-kitabah) adalah bagian dari keterampilan yang harus dikuasai oleh pelajar bahasa Arab.

Ketiga, Dream. Tahapan ini merupakan mimpi atau keinginan atau tujuan yang diharapkan peserta pelatihan dalam mengembangkan keterampilan menulis atau mengetik Arab pada komputer/ laptop. Setelah menemukan beberapa masalah maka langkah selanjutnya adalah merumuskan keinginan atau tujuan untuk lebih memperdalam keterampilan mengetik mahasiswa/i PBA semester II Universitas Nurul Jadid Paiton Probolinggo. Adapun hasil rumusan tujuan atau impian yang diinginkan adalah memberikan pelatihan dan pendampingan selama 2 hari pada mahasiswa tersebut dengan metode yang mudah dipahami dan dipraktekkan sesuai dengan kebutuhan mereka sebagai mahasiswa yang membutuhkan keterampilan menulis/mengetik untuk mencurahkan segala ide-ide dalam pikiran melalui tulisan.

Keempat, Design. Pada tahap ini pelatih atau pelaku dengan para peserta latihan memulai merumuskan strategi, proses dan sistem, membagi peran dan tanggung jawab, 
membuat keputusan dan mengembangkan kolaborasi yang mendukung terwujudnya penyelesaian masalah peserta latihan dan perubahan yang diharapkan dari komunitas dampingan. Adapun hasil design program yang akan dilakukan untuk mewujudkan keinginan, impian atau tujuan yang telah ditetapkan tersebut yaitu:

1) Merumuskan strategi program latihan. Strategi program dampingan berbentuk pelatihan dan pendampingan. Adapun bentuk-bentuk program yang akan dilakukan yaitu: a) pelatihan dan pendampingan dalam mengetik tulisan Arab dengan metode praktis pada mahasiswa/i semester II Prodi PBA Universitas Nurul Jadid

2) Menyusun proses program latihan. Proses penyusunan program latihan berkaitan dengan beberapa hal sebagai berikut: a) waktu pelaksanaannya. Pelaksanaan program tersebut dilaksanakan pada hari selasa-rabu tanggal 16-17 maret 2021, program yang dilakukan adalah pada hari pertama yakni pemberian materi terkait cara mengetik yang benar dan cepat, penginstalan keybord arab pada laptop baik angka arab ataupun huruf arabnya selanjutnya hari kedua praktek mengetik arab secara langsung didampingi pelatih dan para fasilitator kemudian pemberian evaluasi.

Kelima, Deliver atau destiny. Tahap ini adalah tahap dimana setiap orang dalam organisasi mengimplementasikan berbagai hal termasuk pelaksanaan dan pengontrolan atau pengevaluasian program dampingan terhadap peserta yang sudah dirymuskan pada tahap Dream atau Design. Di dalam tahap deliver atau destiny ini, terdapat beberapa tahapan yangakan dilakukan, yaitu sebagai berikut:

1) Tahap pelaksanaan. Sebagaimana waktu kegiatan pelatihan yang telah dilakukan di tahap Design, maka ditemukan bahwa pelatihan mahir mengetik tulisan Arab bagi mahasiswa/i PBA semester II Universitas Nurul Jadid pada hari selasa dan rabu tanggal 16-17 maret 2021 pukul 09.00- selesai. Pelaksanaan tersebut berjalan dengan lancar dan sukses mulai dari Ta' aruf, proses pemberian materi dan proses praktek pelatihan mengetik Arab dan evaluasi.

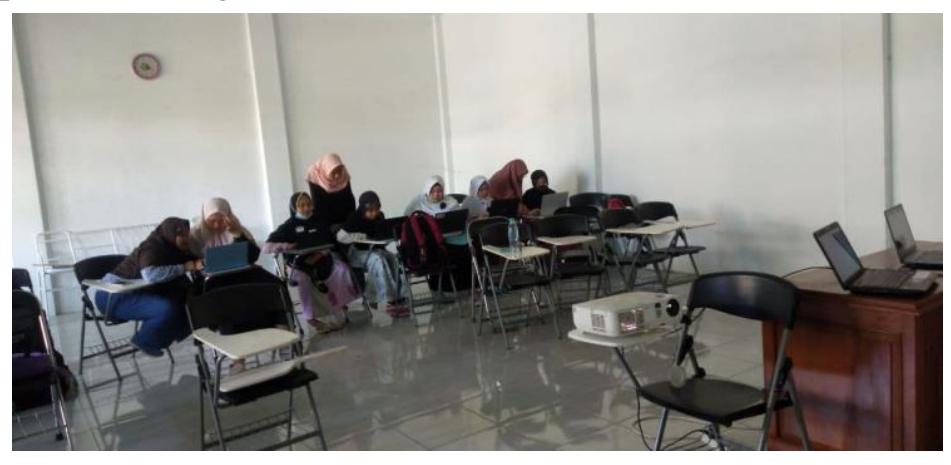

Gambar 1. Mahasiswa menerima materi tentang cara mengetik arab dengan baik dan benar.

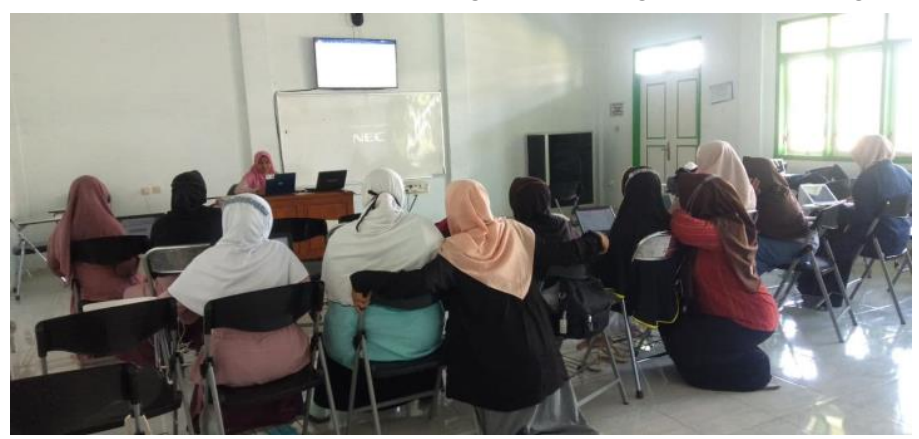

Gambar 2. Mahasiswa/i sedang melaksanakan praktek mengetik Arab secara langsung dan para fasilitator mendampingi proses tersebut. 


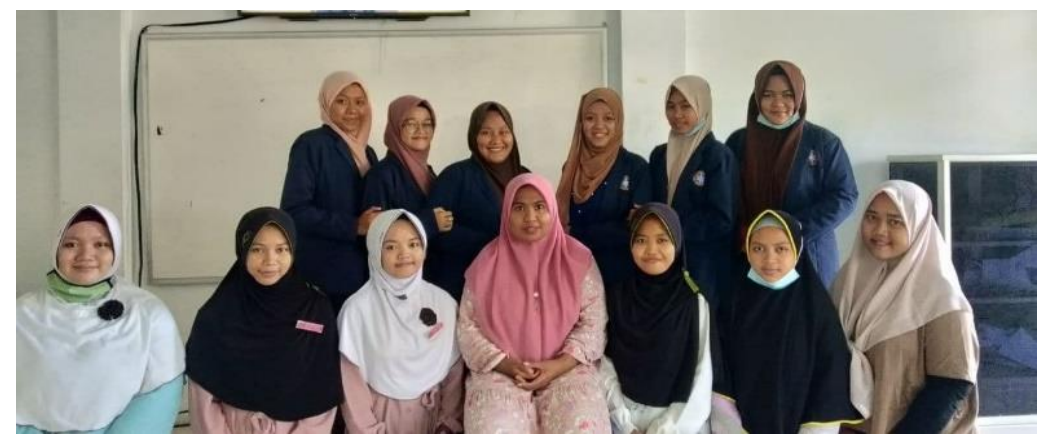

Gambar 3. Para mahasiswi KKN dan DPL foto bersama setelah proses pelatihan

2) Tahap Controlling atau evaluating. Tahap ini dilakukan dua tahap yaitu: a) kontrol atau evaluasi proses pelatihan. Evaluasi pada tahap proses ini dilakukan setiap waktu agar proses pelatihan ini berjalan dengan maksimal seperti mengevaluasi proses penyiapan materi pelatihan yang akan disampaikan dan lain sebagainya. b) kontrol atau evaluasi tahap akhir pelatihan. Evaluasi ini dilakukan setelah proses pelatihan berakhir, evaluasi ini dilakukan untuk melihat apakah proses pelatihan ini berjalan dengan optimal sesuai dengan keinginan dan tujuan yang diharapkan. Berdasarkan evaluai akhir yakni dengan cara pemberian tugas mengetik bahasa Arab sebanyak satu halaman dengan jangka waktu 30 menit tanpa menggunakan huruf arab tempelan keyboard menunjukkan bahwa pelatihan ini $95 \%$ berjalan dengan sukses meskipun ada beberapa peserta yang masih kurang lancar dalam mengetik dengan cepat.

\section{SIMPULAN}

Berdasarkan hasil pelatihan dan pendampingan dapat disimpulkan bahwa kemampuan peserta didik menunjukkan perekembangan yang sangat pesat setelah diadakannya pelatihan mengetik Arab ini hal ini dilihat dari hasil evaluasi yaitu: pertama, kemampuan peserta didik sebelum diadakannya pelatihan ini tergolong rendah, setelah diadakannya pelatihan mengetik ini, kemampuan sebagian besar peserta didik sudah mengalami perubahan yang baik. Kedua, terdapat beberapa kendala yang menyebabkan peserta latihan sulit mengembangkan kemampuannya, yaitu para peserta terbiasa dengan keyboard Bahasa Indonesia sehingga mereka terkadang lupa terhadap tata letak huruf-huruf arab.

\section{SARAN}

Pelatihan atau pendampingan mengetik bahasa Arab sangatlah penting untuk dilakukan lebih lanjut dan mendalam tentunya dengan frekuensi waktu yang lebih lama karena pelatihan selama dua hari yang penulis laksanakan sangatlah kurang mengingat tidak semua mahasiswa bisa hadir full selama dua hari tersebut.

\section{UCAPAN TERIMA KASIH}

Penulis mengucapkan terima kasih kepada Universitas Nurul Jadid umumnya dan kepada pihak LP3M UNUJA khususnya yang telah banyak mensuport kami baik dari segi moril maupun materil dan sudah memberikan kesempatan kepada kami untuk lebih berkembang dalam dunia literasi. Dan untuk para mahasiswa/i PBA UNUJA yang sudah membantu mensukseskan program pelatihan ini.

\section{DAFTAR PUSTAKA}

Andriani, A. (2015). Urgensi Pembelajaran Bahasa. Ta' allum, 3(1): 12-24.

NOR FITRIANI, W. A. R. D. A (2015). Pengembangan Media Visual Flashcard Materi Pokok Kosa Kata Benda- benda dui ruang makan Mata Pelajaran Bahasa Arab Kelas II MI Nurul Ulum Sidorejo Kebonsari Madiun. Jurnal Mahasiswa teknologi Pendidikan, 6(2): 17-22.

Rianggoro, Krisna. 2003. Marilah Belajar Mengetik. Semarang: CV Aneka Ilmu. 
Rizqi, K. (2013) Penggunaan Kartu Gambar dalam meningkatkan kemampuan pelafalan Mufrodat Bahasa Arab pada siswa Tunarungudi SDLB Negeri Ungaran Tahun 2012/2013 (Doctoral dissertation, UniversitasNegeri Semarang).

Setyaningsih, Lina Hartini. 2014. Peningkatan Keterampilan Mengetik Sistem 10 Jari Buta dengan Menggunakan Model Pembelajaran Berbasis Komputer Berbantu Media Typing Master Pada Siswa Kelas X AP SMK Muhammadiyah 01 Pati. Semarang: Universitas Negeri Semarang.

SK Direktur Jenderal Pendidikan Islam No. 3091 tahun 2020 Tentang paradigma Pengabdian Kepada Masyarakat tahun 2020.

Yaqin dkk. (2020). Pendampingan Komunitas Lembaga Pendidikan Bahasa Arab dalam Pembelajaran Al-Mufrodat melalui Media Flash Card di Lembaga Pendidikan Bahasa Arab (LPBA) Al-Qodiri Jember. GUYUB: Journal of Community Engagement 1(3): 167-178 